\title{
Comparison of Re-irradiation Outcomes for Charged Particle Radiotherapy and Robotic Stereotactic Radiotherapy Using CyberKnife for Recurrent Head and Neck Cancers: A Multi-institutional Matched-cohort Analysis
}

\author{
HIDEYA YAMAZAKI ${ }^{1,2}$, YUSUKE DEMIZU ${ }^{3}$, TOMOAKI OKIMOTO ${ }^{3}$, MIKIO OGITA $^{4}$, KENGO HIMEI $^{5}$, \\ SATOAKI NAKAMURA $^{1}$, GEN SUZUKI ${ }^{1}$, KEN YOSHIDA $^{6}$, TADAYUKI KOTSUMA ${ }^{6}$ and YASUO YOSHIOKA ${ }^{7}$ \\ ${ }^{1}$ Department of Radiology, Graduate School of Medical Science, \\ Kyoto Prefectural University of Medicine, Kyoto, Japan; \\ ${ }^{2}$ CyberKnife Center, Soseikai General Hospital, Kyoto, Japan; \\ ${ }^{3}$ Department of Radiology, Hyogo Ion Beam Medical Center, Hyogo, Japan; \\ ${ }^{4}$ Radiotherapy Department, Fujimoto Hayasuzu Hospital, Miyazaki, Japan; \\ ${ }^{5}$ Department of Radiology, Japanese Red Cross Okayama Hospital, Okayama, Japan; \\ ${ }^{6}$ Department of Radiation Oncology, National Hospital Organization Osaka National Hospital, Osaka, Japan; \\ ${ }^{7}$ Department of Radiation Oncology, Osaka University Graduate School of Medicine, Osaka, Japan
}

\begin{abstract}
Aim: To compare survival outcomes for charged particle radiotherapy $(C P)$ and stereotactic body radiotherapy using CyberKnife $(C K)$ in patients who had undergone re-irradiation for head and neck cancers. Patients and Methods: We conducted a retrospective multiinstitutional matched-cohort analysis on 25 patients treated with CP and 25 matched patients treated with CK according to three prognostic factors (nasopharyngeal cancer or not, interval between initial radiotherapy and re-irradiation, and planning target volume). Results: CP was used more often to treat non-squamous cell cancer ((non-SCC): 52\% vs. 0\%) with a higher prescribed dose (median=57.6 Gy(RBE)/16 fractions) than $C K(32 \mathrm{~Gy} / 5$ fractions $)$. The local control rate $(L C)$ for patients treated with $C P$ was $71.2 \%$ at 1 year and that for patients treated with $C K$ was $63.8 \%(p=0.24)$. The 1-year overall survival (OS) rates were $67.1 \%$ for $C P$ and $36.3 \%$ for CK $(p=0.0002)$, respectively. Non-SCC patients showed better OS rates at 1 year than SCC patients. In the SCC sub-group analysis, the 1-year LC, OS rates were
\end{abstract}

Correspondence to: Hideya Yamazaki, MD, Department of Radiology, Kyoto Prefectural University of Medicine, 465 Kajiicho Kawaramachi Hirokoji, Kamigyo-ku, Kyoto, Kyoto 602-8566, Japan. Tel: +81 752515618, Fax: +81 752515840, e-mail: hideya10@hotmail.com

Key Words: Head and neck cancer, re-irradiation, stereotactic radiotherapy, charged particle radiotherapy.
$65 \%, 58.3 \%$ in the CP group and $64 \%, 36.3 \%$ in the $C K$ group ( $p=0.81, p=0.02)$, respectively. A total of 16 patients (32\%) experienced grade 3 or worse toxicities (24\% in CK and $40 \%$ in $C P, p=0.36)$, including six grade 5 toxicities. Conclusion: $C P$ produced higher survival rates than $C K$, treated more non-SCC patients and used a higher prescribed dose. On the other hand, severe toxicities occurred in both groups, which, however, require further investigation.

Recent progress in the treatment of head and neck cancers, particularly advances in treatment modalities and chemotherapy, has enabled patients to survive for more than 5 years (1). However, in-field recurrence is one of the major obstacles to a cure (1-3). As only $20-30 \%$ of patients are candidates for salvage surgery $(3,4)$, chemotherapy is still the mainstay treatment for patients after locoregional failure with a median survival time of 6-10 months. Re-irradiation has emerged as a potentially curative therapy with the advent of modern radiotherapy techniques, such as intensitymodulated radiotherapy and stereotactic body radiotherapy (SBRT) (5). CyberKnife (CK) is a nearly real-time imageguided SBRT system suitable for precise dose delivery over short treatment periods. Several groups have investigated treatment with $\mathrm{CK}$, including ours, and have demonstrated reduced acute toxicity due to short treatment periods and limited irradiation fields (6-9).

Charged particle radiotherapy (CP) treatments, such as proton and carbon ion radiotherapy, have a greater energy deposition than photon beams, delivering maximum dose at 
precise depth, generating the Bragg peak. Compared with conformal radiotherapy, $\mathrm{CP}$, thus, creates an inherently threedimensional conformal dose distribution without exposing the surrounding normal tissue to extra doses (10). Although $\mathrm{CP}$ has been available in the clinical setting for decades, it is difficult to compare the outcomes of photon and $\mathrm{CP}$ because of heterogeneity of institutions and the lack of prospective comparison studies. Therefore, the aim of this study was to compare the survival outcomes for patients treated with $\mathrm{CP}$ and $\mathrm{CK}$ using a matched-pair method. Previously, we have found three important prognostic factors; the primary site (nasopharynx or not), planning target volume (PTV) and treatment interval are all important prognostic factors for survival after re-irradiation for recurrent head and neck cancers (11) and, therefore, we conducted a 1:1 case matched-cohort study using those three factors with data from multi-institutional charts to compare $\mathrm{CP}$ and $\mathrm{CK}$ outcomes and assess the influence of the factors listed above.

\section{Patients and Methods}

We included patients with recurrent head and neck tumors treated at the Soseikai General, Fujimoto Hayasuzu, Okayama Kyokuto, Osaka University Hospitals and Hyogo Ion Beam Medical Center (HIBMC) between 2000 and 2010. All recurrences occurred in an area previously irradiated with $\geq 40 \mathrm{~Gy}$. The charged particle beam dose is reported in Gy (relative biological effectiveness (RBE)), which is the physical dose multiplied by RBE of the protons or carbon ions. We excluded patients who underwent re-irradiation as a planned boost after conventional external radiotherapy and those with other disease sites outside the re-irradiation area. The first course of radiotherapy was delivered by either X-ray therapy or charged particle therapy with either a curative intent or delivery of postoperative radiotherapy. A total of 25 patients were treated with $\mathrm{CP}$ and we chose 25 case-matched $\mathrm{CK}$ patient pairs according to primary site (nasopharynx or not), interval between initial radiotherapy and re-irradiation ( $\leq 30$ months or $>30$ months) and PTV ( $\leq 40 \mathrm{~cm}^{3}$ or $>40 \mathrm{~cm}^{3}$ ) from 107 patients treated with CK (11). The median age of patients was 59 years (range $=19-88$ ), including 36 males and 14 females. The most common primary site was the nasal or paranasal sinus. Cut-off values of each variable were applied from a previous study (11). The patients had a follow-up of at least 5 months (for survivor) and the median follow-up period was 8 (range $=0.4-54.5$ ) months.

CK re-irradiation was performed using the CK system. Patients were treated with a median dose of $32 \mathrm{~Gy}($ range $=25-39)$ in a median of five fractions (range $=3-8$ ) prescribed as D90, D95 or a marginal dose. D90 and D95 doses were defined by a minimum dose covering $90 \%$ and $95 \%$, respectively, of PTV. The marginal dose was defined as the percentage $(100 \%=$ maximum dose $)$ of an isodose curve covering PTV. The gross tumor volume (GTV) was defined as the visible tumor in the imaging studies. No additional margin was added for clinical target volume (CTV=GTV). Determination of PTV was made by physicians in each institution $(\mathrm{PTV}=\mathrm{CTV}+0-3 \mathrm{~mm})$. The most frequently used doses were 30 Gy in five fractions $(n=5), 35$ Gy in five fractions $(n=4), 37$ Gy in
8 fractions $(n=3), 30$ Gy in 8 fractions $(n=2)$ and 32 Gy in five fractions $\mathrm{Gy}(\mathrm{n}=2)$. No patient underwent concurrent chemotherapy during treatment.

Details of the CP protocol at HIBMC have been described elsewhere $(10,12-14)$. In brief, after a custom-made thermoplastic cast was used to immobilize each patient in the supine position with an adequate head angle, $1 \mathrm{~mm}$ computed tomography (CT) slices and 1-3 mm magnetic resonance imaging (MRI) slices were obtained. Re-irradiation treatments were planned on a CT-based three-dimensional treatment planning system (FOCUS-M CMS, St. Louis, MO, USA and Mitsubishi Electric, Tokyo, Japan) until April 2008 and Xio-M (FOCUS-M CMS and Mitsubishi Electric) from May 2008. The target volumes and organs at risk were delineated on the CT-MRI fusion images. CTV was generally defined as GTV plus a $5 \mathrm{~mm}$ basic margin. PTV was defined as CTV plus a setup margin of $3 \mathrm{~mm}$. CP was delivered daily (five doses per week) to the isodose encompassing PTV.

Toxicity was evaluated using the National Cancer Institute Common Toxicity Criteria scale version 3.0. The biologically equivalent dose was calculated as the equivalent of $2 \mathrm{~Gy}$ fractions (EQD2) using a linear-quadratic model, where $\alpha / \beta=10$ for tumors and $\alpha / \beta=3$ for organs at risk. EQD2 was calculated by (prescribed dose $\times(\alpha / \beta+$ dose per fraction $)) /(\alpha / \beta+2)$.

Biological effects of $\mathrm{CP}$ at HIBMC were evaluated in vitro and in vivo where the $\mathrm{RBE}$ values for proton and carbon ion irradiation were determined to be 1.1 and 2-3.7 (depending on the depth in the spread-out Bragg peaks), respectively (15). In this article, however, all doses are reported in Gy to avoid confusion.

Statistical analysis. All statistical analyses were performed using Stat-view 5.0 statistical software (SAS Institute, Inc., Cary, NC, USA). Percentages were analyzed using the $\chi^{2}$ test and values were compared using the Mann-Whitney $U$-text. The durations of survival were calculated from the first day of reirradiation. Actuarial survival curves were generated using the Kaplan-Meier method and comparisons were made using the log-rank test. Cox's proportional hazard model was used for the multivariate analysis (variables $p<0.1$ in univariate analysis were inserted). All analyses used the $p<0.05$ level of significance unless otherwise indicated.

\section{Results}

Patients' and disease characteristics of patients treated with $\mathrm{CP}$ and $\mathrm{CK}$ are listed in Table I. CP was used to treat more non-squamous cell cancer (non-SCC) patients $(52 \%)$ than CK $(0 \%)$ with higher prescribed doses of $57.6 \mathrm{~Gy}(\mathrm{RBE})$ (range $=43.2-70.2)$ in 16 fractions $\quad($ range $=12-30)$ $(\mathrm{EQD} 2=65.2$ (range=48.9-74.2) $\mathrm{Gy}(\mathrm{RBE}))$ than $32 \mathrm{~Gy}$ (range $=25-39)$ in five fractions $(3-8$ fractions) $(\mathrm{EQD} 2=41.9$ (range=30.0-74.7) Gy), respectively. The local control rates for patients treated with $\mathrm{CP}$ and $\mathrm{CK}$ at 1 year were $71.2 \%$ (95\% confidence interval $(\mathrm{CI})=51.4 \%-91.0 \%)$ and $57.7 \%$ $(\mathrm{CI}=37.4-78.0 \%)$, respectively $(p=024)$ (Figure 1a). The 1year overall survival (OS) rates were $67.1 \%$ (CI=48.3\%$85.9 \%$ ) (MST $=24.4$ months) in the $\mathrm{CP}$ group and $36.3 \%$ $(\mathrm{CI}=16.4 \%-56.3 \%)(\mathrm{MST}=6.6$ months $)$ in the $\mathrm{CK}$ group $(p=0.0002)$ (Figure 1b). Univariate analysis revealed that the modality ( $\mathrm{CP}$ better than $\mathrm{CK}$ ), histology (non-SCC better 
Table I. Characteristics and treatment factors of patients.

\begin{tabular}{|c|c|c|c|c|c|c|}
\hline \multirow[t]{2}{*}{ Variables } & \multirow[t]{2}{*}{ Strata } & $\begin{array}{c}\text { Charged particle } \\
\text { (CP) } \\
\mathrm{n}=25\end{array}$ & $(\%)$ & $\begin{array}{l}\text { CyberKnife } \\
\qquad \begin{array}{l}\text { (CK) } \\
\mathrm{n}=25\end{array}\end{array}$ & \multirow[t]{2}{*}{$(\%)$} & \multirow[t]{2}{*}{$p$-Value } \\
\hline & & $\begin{array}{l}\text { No. or Median } \\
\quad \text { (range) }\end{array}$ & & $\begin{array}{l}\text { No. or Median } \\
\quad \text { (range) }\end{array}$ & & \\
\hline Age & & $55(19-82)$ & & $61(42-88)$ & & 0,0424 \\
\hline \multirow[t]{2}{*}{ Gender } & Female & 10 & $(40 \%)$ & 4 & $(16 \%)$ & NS \\
\hline & Male & 15 & $(60 \%)$ & 21 & $(84 \%)$ & \\
\hline \multirow[t]{7}{*}{ Primary site } & Nasopharynx & 3 & $(12 \%)$ & 3 & $(12 \%)$ & ${ }^{\#} \mathrm{NS}$ \\
\hline & Other & 22 & $(88 \%)$ & 22 & $(88 \%)$ & \\
\hline & Oral & 2 & $(9 \%)$ & 4 & $(9 \%)$ & \\
\hline & Oro-hypopharynx & 0 & $(0 \%)$ & 9 & $(20 \%)$ & \\
\hline & Salivary gland & 3 & $(13 \%)$ & 0 & $(0 \%)$ & \\
\hline & Nasal and paranasal sinus & 15 & $(65 \%)$ & 9 & $(20 \%)$ & \\
\hline & External ear, lacrimal gland & 2 & $(9 \%)$ & 0 & $(0 \%)$ & \\
\hline \multirow[t]{2}{*}{ Interval from initial radiotherapy } & $\leq 30$ months & 19 & $(76 \%)$ & 19 & $(76 \%)$ & \#NS \\
\hline & 30 months $<$ & 6 & $(24 \%)$ & 6 & $(24 \%)$ & \\
\hline \multirow[t]{6}{*}{ Histology } & Squamous cell carcinoma & 12 & $(48 \%)$ & 25 & $(100 \%)$ & $<0.001$ \\
\hline & Other & 13 & $(52 \%)$ & 0 & $(0 \%)$ & \\
\hline & Melanoma & 3 & $(20 \%)$ & 0 & $(0 \%)$ & \\
\hline & Adenoid cystic ca. & 7 & $(47 \%)$ & 0 & $(0 \%)$ & \\
\hline & Undif ca., Alveolar & 3 & $(20 \%)$ & 0 & $(0 \%)$ & \\
\hline & $\begin{array}{c}\text { rhabdomyosarcoma, } \\
\text { Adeno ca. }\end{array}$ & & & & & \\
\hline \multirow[t]{2}{*}{ Planning target volume } & $\leq 40 \mathrm{~cm}^{3}$ & 4 & $(16 \%)$ & 4 & $(16 \%)$ & ${ }^{\#} \mathrm{NS}$ \\
\hline & $<40 \mathrm{~cm}^{3}$ & 21 & $(84 \%)$ & 21 & $(84 \%)$ & \\
\hline \multirow[t]{2}{*}{ Surgical history } & $(-)$ & 16 & $(64 \%)$ & 12 & $(48 \%)$ & NS \\
\hline & $(+)$ & 9 & $(36 \%)$ & 13 & $(52 \%)$ & \\
\hline Prescribed dose (Gy(RBE) and Gy) & & $57.6(43.2-70.2)$ & & $32(25-39)$ & & $<0.0001$ \\
\hline Number of fractions & & $16(12-30)$ & & $5(3-8)$ & & \\
\hline EQD2 (Gy or Gy(RBE) $(\alpha / \beta=10))$ & & $65.2(48.9-74.2)$ & & $41.9(30.0-74.7)$ & & $<0.0001$ \\
\hline Prescribed previous dose (Gy(RBE) or Gy) & & $64(30-74.3)$ & & $60(40-116)$ & & NS \\
\hline Previous number of fractions & & $30(5-26)$ & & $30(20-57)$ & & \\
\hline *Cumulative EQD 2 Gy $(\mathrm{Gy}(\mathrm{RBE})$ or $\mathrm{Gy})(\alpha / \beta=10))$ & & $131(90-142)$ & & $100(66-151)$ & & $<0.0001$ \\
\hline
\end{tabular}

EQD2, biological effective dose in 2 Gy fraction; *summation of previous radiotherapy and re-irradiation; \#adjusted variables. Bold values indicate statistical significance.

than SCC) and higher prescribed doses (better than lower prescribed dose) were the significant predisposing factors for OS (Table II). Non-SCC patients showed an OS outcome of $75.2 \%(\mathrm{CI}=50.6-99.8 \%, \mathrm{MST}=36.8$ months $)$ at 1 year, which was better than the $42.6 \%(\mathrm{CI}=25.7-59.4 \%, \mathrm{MST}=7.4$ months) of the SCC patients ( $p=0.003$ ) (Figure 2). No factor remained in the multivariate analysis as a statistically significant predictor for OS.

SCC patients. A subgroup analysis was undertaken for SCC patients. There were no statistically significant differences in gender, primary site, PTV and treatment interval between $\mathrm{CP}$ $(n=12)$ and CK groups $(n=25)$. The $\mathrm{CP}$ group received higher prescribed doses $($ median=57.6 Gy $($ range=43.2-70.2) $)$ than the CK group (median=32 Gy (range=25-39)). The local control rate for patients treated with $\mathrm{CK}$ and $\mathrm{CP}$ at 1 year was $63.8 \%$ $(\mathrm{CI}=43.1-84.4 \%)$ and $71.2 \%(\mathrm{CI}=51.4 \%-91.0 \%)$, respectively, (not significant (NS), $p=0.81$ ) (Figure 3a). The 1-year OS rates were $58.3 \%(\mathrm{CI}=48.3 \%-85.9 \%)$ in the $\mathrm{CP}$ group and $36.3 \%$ $(16.4 \%-56.3 \%)$ in the CK group $(p=0.02)$ (Figure $3 b)$.

Toxicity. A total of 16 patients (32\%) presented with grade 3 or worse toxicities (24\% of patients treated with CK and $40 \%$ of patients treated with CP; NS), including six grade 5 toxicities. There were five incidences of bleeding, resulting in four deaths (grade 5) (Table III). Two fistulas, four skin or soft tissue and/or bone necrosis (with or without infection), two ulcerations (with or without pain), two nerve palsies, as well as two visual disturbances were observed. In patients with previous surgical historv, 41\% (9/22) 


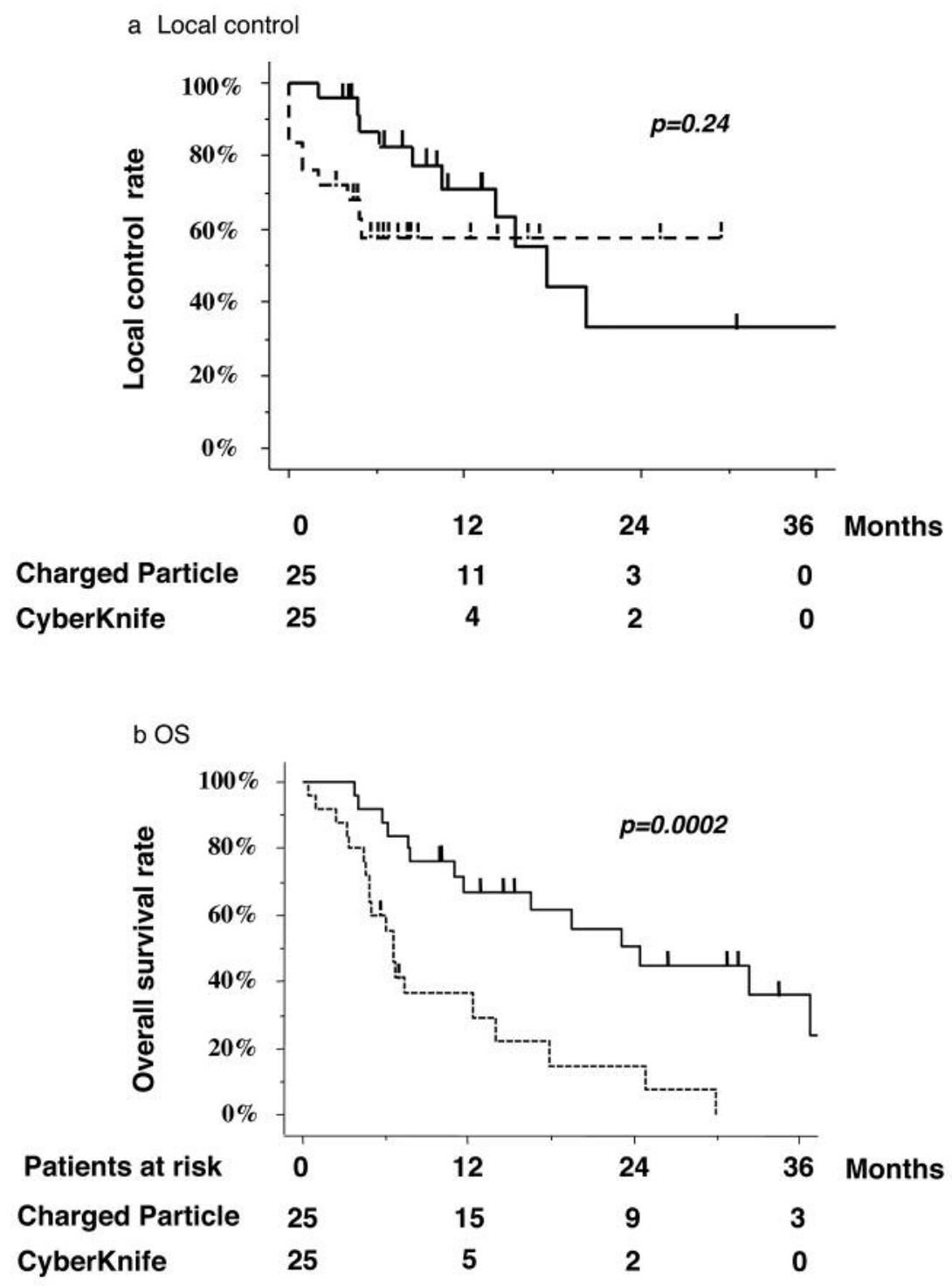

Figure 1. Local control rate and overall survival rate for charged particle radiotherapy (CP) and CyberKnife (CK). a) Local control rate. b) Overall survival rate. The thick line depicts $C P$ and the thin line depicts CK. SBRT, Stereotactic body radiotherapy.

Table II. Results of uniivariate analysis according to overall survival after re-irradiation.

Overall survival

\begin{tabular}{|c|c|c|c|c|}
\hline \multirow[b]{2}{*}{ Variable } & \multirow[b]{2}{*}{ Strata } & \\
\hline & & Hazard ratio & $95 \%$ confidence interval & $p$-Value \\
\hline Modality & CK vs. CP & 3.783 & $1.798-7.960$ & 0.0005 \\
\hline Gender & Male vs. Female & 0.753 & $0.347-1.635$ & 0.473 \\
\hline Age & & 1.003 & $0.978-1.029$ & 0.8227 \\
\hline Histology & SCC $v s$. non-SCC & 0.255 & $0.096-0.679$ & 0.0062 \\
\hline Prescribed dose (EQD2) (Gy) & & 0.952 & $0.927-0.977$ & 0.0002 \\
\hline Previous surgical intervention & yes $v s$. no & 0.9 & $0.446-1.816$ & 0.768 \\
\hline
\end{tabular}

EQD2, Biologically equivalent dose calculated into equivalent $2-G y$ fractions $\alpha / \beta=10$. Bold values indicate statistical significance. 
a LC SCC vs. non-SCC

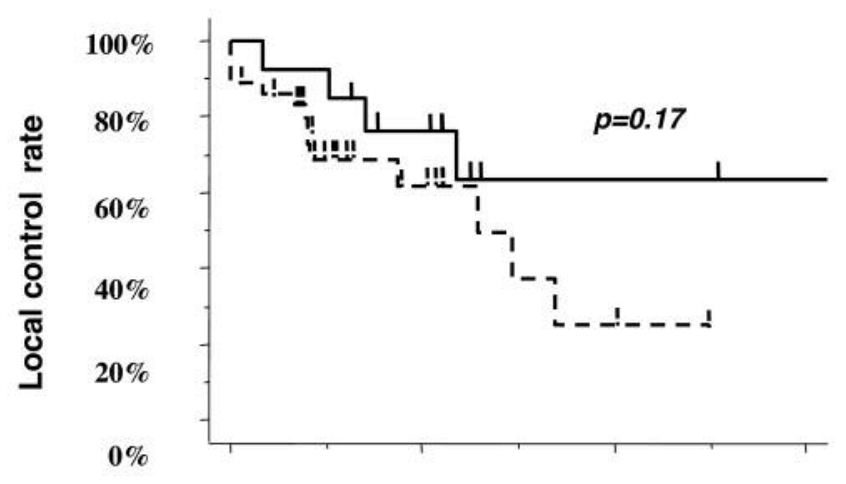

$\begin{array}{lccccc}\text { Patients at risk } & 0 & 12 & 24 & 36 \text { Months } \\ \text { Non-SCC } & 13 & 7 & 3 & 1 & \\ \text { SCC } & 37 & 8 & 2 & 0\end{array}$

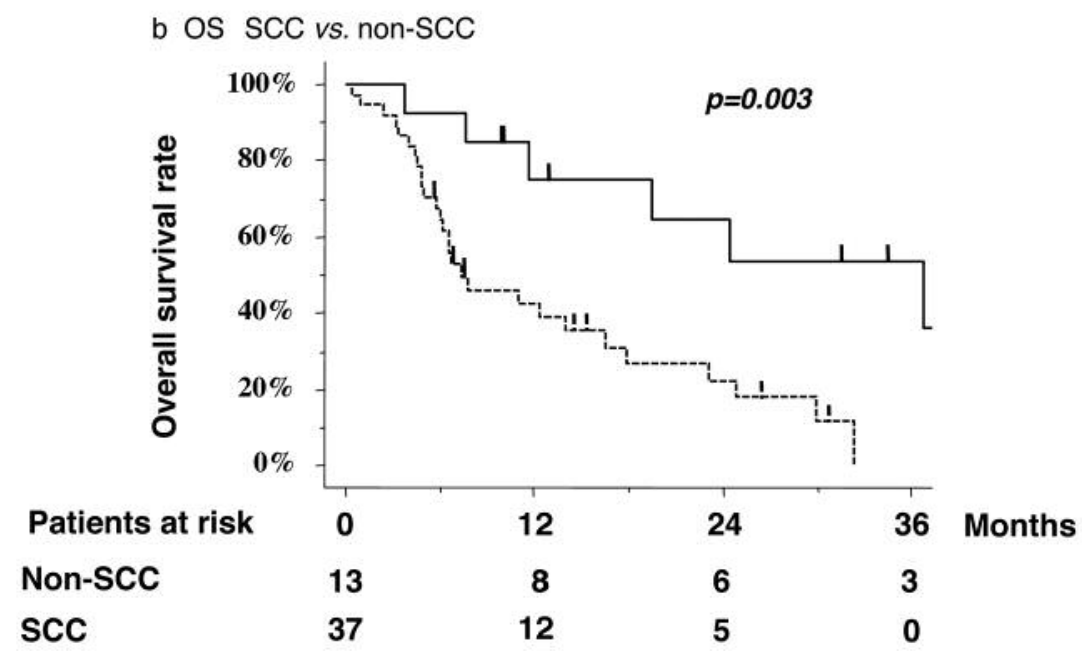

Figure 2. Local control rate and overall survival rate for squamous cell carcinoma (SCC) and others (non-SCC). a) Local control rate. b) Overall survival rate. The thick line depicts non-SCC patients and the thin line depicts SCC patients.

Table III. Toxicity of re-irradiation.

\begin{tabular}{|c|c|c|c|c|c|c|c|}
\hline Grade & CyberKnife (CK) & & & Charged particle $(\mathrm{CP})$ & & & $p$-Value \\
\hline $0-2$ & 19 & $(76 \%)$ & & 15 & $(60 \%)$ & & NS (0.36) \\
\hline \multirow[t]{2}{*}{3} & 4 & $(16 \%)$ & Ulceration and bleeding (1) & 3 & $(12 \%)$ & Nerve palsy (2) & \\
\hline & & & Soft tissue necrosis (1) Fistula (2) & & & Ulceration and pain (1) & \\
\hline \multirow[t]{2}{*}{4} & 0 & $(0 \%)$ & & 3 & $(12 \%)$ & Visual disturbance (2) & \\
\hline & & & & & & Soft tissue necrosis (1) & \\
\hline \multirow[t]{3}{*}{5} & 2 & $(8 \%)$ & Bleeding (2) & 4 & $(16 \%)$ & Bleeding (2) & \\
\hline & & & & & & $\begin{array}{l}\text { Skin/bone necrosis } \\
\text { and infection (1) }\end{array}$ & \\
\hline & & & & & & $\begin{array}{l}\text { Soft tissue necrosis } \\
\text { and infection (1) }\end{array}$ & \\
\hline
\end{tabular}

NS, Not significant. 


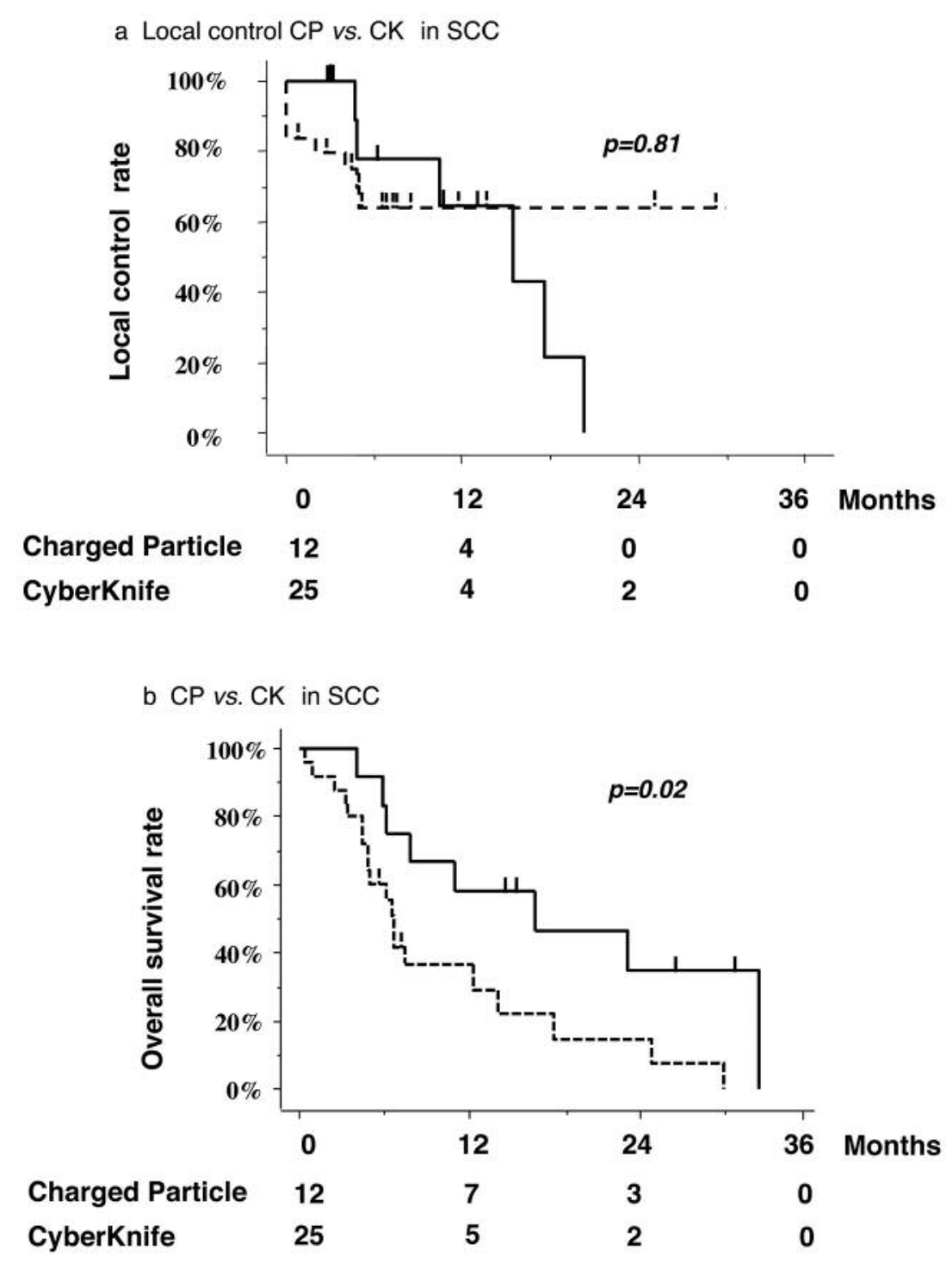

Figure 3. Local control rate and overall survival rate for charged particle radiotherapy (CP) and CyberKnife (CK) in SCC subpopulation. a) Local control rate. b) Overall survival rate. The thick line depicts $C P$ and the thin line depicts $C K$. SCC, squamous cell carcinoma.

experienced toxicities of grade 3 or worse, whereas only $25 \%(7 / 28)$ of patients without previous surgical histories were grade 3 or worse $(p=0.36)$.

\section{Discussion}

This is the first study comparing outcomes for $\mathrm{CP}$ and photon SBRT. Previously reported prognostic factors after re-irradiation include nasopharyngeal primary site versus other sites $(16,17)$, radiotherapy interval $(6,18)$, irradiated dose $(17,19)$, tumor volume $(8,20)$, tumor burden $(21)$, resectability $(17,19,22)$ and mucosal ulceration (11). As we found three prognostic factors (nasopharyngeal cancer or not, interval between initial radiotherapy and re-irradiation, as well as planning target volume), we adjusted those factors in $\mathrm{CP}$ and CK patients accordingly (11). We showed that CP resulted in a superior OS rate compared to that with $\mathrm{CK}$, not only in the total population but also in the SCC subgroup analysis. Furthermore, the local control rate showed better tendency in patients treated with CP than in patients treated with CK. In a previous analysis, we found that small volume nasopharyngeal cancer after long disease-free period could enjoy better outcome. Actually, two long survivors (more than two years) with primary tumor control in CK group 
were all nasopharyngeal cancer patients, which elevated outcome of CK group. The question arose as to whether this superiority of CP was dependent on the prescribed dose or other factors. If increased prescribed doses could improve outcomes, we should make an effort to increase prescribed doses for patients treated with CK.

There were cases of higher than grade 3 toxicities in both groups, suggesting that future investigation is required. A total of 16 patients $(32 \%)$ presented with grade 3 or worse toxicities (24\% in CK vs. $40 \%$ in CP; NS), including six grade 5 toxicities. We performed a toxicity analysis after a previous study that focused on carotid blow-out syndrome in patients treated with $\mathrm{CK}$ (24) and showed that more than $10 \%$ patients suffered lethal bleeding after reirradiation. We found that greater than $50 \%$ of carotid invasion, mucosal ulceration and lymph node area irradiation could be risk factors related to bleeding. Similar tactics could also be applied to reduce toxicity in patients treated with $\mathrm{CP}$. A phase I/II dose escalation study using SBRT for patients without the risk factors listed above is required. Furthermore, additional chemotherapeutic agents ( $\mathrm{S}-1$ or cetuximab, etc.) could also be explored to enhance efficacy.

There were several limitations in this study. First, this is a retrospective study dealing with a small number of patients and limited follow-up periods. Next, there may be a huge selection bias to compare the results in disease histology. CP is generally indicated for the less common histological subtypes, such as adenocarcinomas, adenoid cystic carcinomas and malignant melanomas, as these histological subtypes are considered to be relatively resistant to conventional photon radiotherapy (23). As a results, CP treated 13 non-SCC patients and $\mathrm{CK}$ none. Although survival benefit in SCC subgroup analysis between $\mathrm{CP}$ and $\mathrm{CK}$ was also found, the current study represents a preliminary analysis that needs to be further investigated. Finally, we were unable to examine the details of previous chemotherapy and/or surgery because of the large heterogeneity in reporting practices between institutions. Despite potential economical barriers, a prospective trial with a larger number of patients and longer follow-up period should be performed to confirm our findings.

In conclusion, $\mathrm{CP}$ produced higher survival rates than $\mathrm{CK}$, treated more non-SCC patients and used a higher prescribed dose. On the other hand, severe toxicities occurred in both groups, which require further investigation.

\section{Conflicts of Interest}

None.

\section{References}

1 Mazeron R, Tao Y, Lusinchi A and Bourhis J: Current concepts of management in radiotherapy for head and neck squamous-cell cancer. Oral Oncol 45: 402-408, 2009.
2 Vokes EE, Weichselbaum RR, Lippman SM and Hong WK: Head and neck cancer. N Eng J Med 328: 184-194, 1993.

3 Temam S, Pape E, Janot F, Wibault P, Julieron M, Lusinchi A, Mamelle G, Marandas P, Luboinski B and Bourhis J: Salvage surgery after failure of very accelerated radiotherapy in advanced head-and-neck squamous cell carcinoma. Int J Radiat Oncol Biol Phys 62: 1078-1083, 2005.

4 Wong SJ, Machtay M and Li Y: Locally recurrent, previously irradiated head and neck cancer: concurrent reirradiation and chemotherapy, or chemotherapy alone? J Clin Oncol 24: 2653$2658,2006$.

5 Hoebers F, Heemsbergen W, Moor S, Lopez M, Klop M, Tesselaar $\mathrm{M}$ and Rasch $\mathrm{C}$ : Reirradiation for head-and-neck cancer: delicate balance between effectiveness and toxicity. Int J Radiat Oncol Biol Phys 81: e111-118, 2011.

6 Kodani N, Yamazaki H, Tsubokura T, Shiomi H, Kobayashi K, Nishimura T, Aibe N, Ikeno H and Nishimura T: Stereotactic body radiation therapy for head and neck tumor: Disease control and morbidity outcomes. J Radiat Res 52: 24-31, 2011.

7 Cengiz M, Ozyigit G, Yazici G, Doğan A, Yildiz F, Zorlu F, Gürkaynak M, Gullu IH, Hosal S and Akyol F: Salvage reirradiaton with stereotactic body radiotherapy for locally recurrent head-andneck tumors. Int J Radiat Oncol Biol Phys 81: 104-109, 2011.

8 Vargo JA, Ferris RL, Ohr J, lump DA, Davis KS, Duvvuri U, Kim S, Johnson JT, Bauman JE, Gibson MK, Branstetter BF and Heron DE: A prospective phase 2 trial of reirradiation with stereotactic body radiation therapy plus cetuximab in patients with previously irradiated recurrent squamous cell carcinoma of the head and neck. Int J Radiat Oncol Biol Phys 91: 480-488, 2015.

9 Lartigau EF, Tresch E, Thariat J, Graff P, Coche-Dequeant B, Benezery K, Schiappacasse L, Degardin M, Bondiau PY, Peiffert D, Lefebvre JL, Lacornerie T and Kramar A: Multi institutional phase II study of concomitant stereotactic reirradiation and cetuximab for recurrent head and neck cancer. Radiother Oncol 109: 281-285, 2013.

10 Takagi M, Demizu Y, Hashimoto N, Mima M, Terashima K, Fujii O, Jin D, Niwa Y, Morimoto K, Akagi T, Daimon T, Sasaki R, Hishikawa Y, Abe M, Murakami M and Fuwa N: Treatment outcomes of particle radiotherapy using protons or carbon ions as a single-modality therapy for adenoid cystic carcinoma of the head and neck. Radiother Oncol 113: 364-370, 2014.

11 Yamazaki H, Ogita M, Himei K, Nakamura S, Suzuki G, Yoshida K, Kotsuma T and Yoshioka Y: Reirradiation using robotic image-guided stereotactic radiotherapy of recurrent head and neck cancer. J Radiat Res 57: 288-293, 2016.

12 Morimoto K, Demizu Y, Hashimoto N, M Mima M, Terashima K, Fujii O, Otsuki N, Murakami M, Fuwa N and Nibu K: Particle radiotherapy using protons or carbon ions for unresectable locally advanced head and neck cancers with skull base invasion. Jpn J Clin Oncol 44: 428-434, 2014.

13 Miyawaki D, Murakami M, Demizu Y, Sasaki R, Niwa Y, Terashima K, Nishimura H, Hishikawa $Y$ and Sugimura K: Brain injury after proton therapy or carbon ion therapy for head-andneck cancer and skull base tumors. Int J Radiat Oncol Biol Phys 75: 378-384, 2009.

14 Demizu Y, Fujii O, Terashima K, Mima M, Hashimoto N, Niwa Y, Akagi T, Daimon T, Murakami M and Fuwa N: Particle therapy for mucosal melanoma of the head and neck. A singleinstitution retrospective comparison of proton and carbon ion therapy. Strahlenther Onkol 190: 186-191, 2014. 
15 Kagawa K, Murakami M, Hishikawa Y, Abe M, Akagi T, Yanou T, Kagiya G, Furusawa Y, Ando K, Nojima K, Aoki M and Kanai T: Preclinical biological assessment of proton and carbon ion beams at Hyogo Ion Beam Medical Center. Int J Radiat Oncol Biol Phys 54: 928-938, 2002.

16 Lee N, Chan K, Bekelman JE, Zhung J, Mechalakos J, Narayana A, Wolden S, Venkatraman ES, Pfister D, Kraus D, Shah J and Zelefsky MJ: Salvage reirradiation for recurrent head and neck cancer. Int J Radiat Oncol Biol Phys 68: 731-740, 2007.

17 Ohizumi Y, Tamai Y, Imamiya S and Akiba T: Prognostic factors ofreirradiation for recurrent head and neck cancer. Am J Clin Oncol 25: 408-413, 2002.

18 Spencer SA, Harris J, Wheeler RH, Machtay M, Schultz C, Spanos W, Rotman M, Meredith R and Ang KK: Final report of RTOG 9610, a multiinstitutional trial of reirradiation and chemotherapy for unresectable recurrent squamous cell carcinoma of the head and neck. Head Neck 30: 281-288, 2008.

19 Salama JK, Vokes EE, Chmura SJ, Milano MT, Kao J, Stenson KM, Witt ME and Haraf DJ: Long-term outcome of concurrent chemotherapy and reirradiation for recurrent and second primary head-and-neck squamous cell carcinoma. Int J Radiat Oncol Biol Phys 64: 382-339, 2006.

$20 \mathrm{Wu}$ SX, Chua DT, Deng ML, Zhao C, Li FY, Sham JS, Wang HY, Bao Y, Gao YH and Zeng ZF: Outcome of fractionated stereotactic radiotherapy for 90 patients with locally persistent and recurrent nasopharyngeal carcinoma. Int J Radiat Oncol Biol Phys 69: 761-769, 2007.
21 Tanvetyanon T, Padhya T, McCaffrey J, Zhu W, Boulware D, Deconti R and Trotti A: Prognostic factors for survival after salvage reirradiation of head and neck cancer. J Clin Oncol 27: 1983-1991, 2009.

22 Unger KR, Lominska CE, Deeken JF, Davidson BJ, Newkirk KA, Gagnon GJ, Hwang J, Slack RS, Noone AM and Harter KW: Fractionated stereotactic radiosurgery for reirradiation of head-andneck cancer. Int J Radiat Oncol Biol Phys 77: 1411-1419, 2010.

23 Schulz-Ertner D, Jäkel O and Schlegel W: Radiation therapy with charged particles. Semin Radiat Oncol 16: 249-259, 2006.

24 Yamazaki H, Ogita M, Kodani N, Nakamura S, Kotsuma T, Yoshida $\mathrm{K}$ and Yoshioka Y: Carotid blowout syndrome in Pharyngeal Cancer Patients treated by hypofractionated stereotactic re-irradiation using CyberKnife: A multi-institutional matched-cohort analysis. Radiother Oncol 115: 67-71, 2015.

Received August 24, 2016

Revised September 5, 2016

Accepted September 6, 2016 